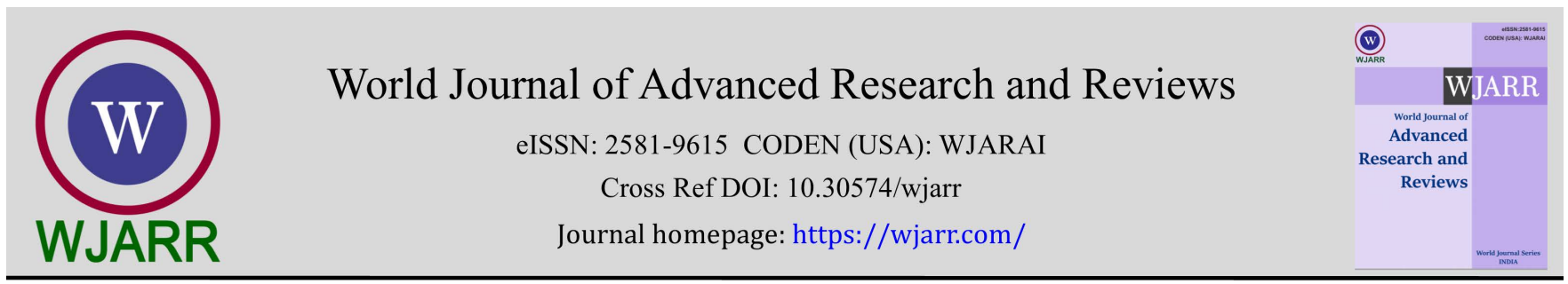

(REVIEW ARTICLE)

Check for updates

\title{
The interdisciplinary nexus between art and science and the play of the aesthetic
}

\author{
Daniel Shorkend * \\ Technion Institute of Technology, Haifa, Israel. \\ World Journal of Advanced Research and Reviews, 2022, 13(01), 617-625 \\ Publication history: Received on 19 December 2021; revised on 22 January 2022; accepted on 24 January 2022 \\ Article DOI: https://doi.org/10.30574/wjarr.2022.13.1.0079
}

\begin{abstract}
It is usually assumed that each discipline ranging from the humanities to the sciences forms a neat, separate and irreducible mode of analysis and area of expertise. The great body of knowledge accumulated over time, is a testimony to the many advances in each field. Often new fields and sub fields are established, but in the main there appears to be a separation between the humanities and the sciences; two cultures as it has often been described. While this is a useful partition, it may be but a fiction. For whether one is talking about either such disciplines, it remains human knowledge all the same and therefore subject to the same perceptual apparatus and history, albeit science claims neutrality and objectivity, while the humanities and the arts, the subjective and more imaginative domain. Nevertheless, such distinctions may be spurious and shortsighted. My endeavor is to suggest some rudimentary language, albeit far from a written system of codification or discipline, but described as a more holistic conception of the "state of knowledge" as it were. It is here that one may speak of the inter-disciplinary and I do this by some philosophical speculations wherein art and science can share a common language of sorts.
\end{abstract}

Keywords: Art; Aesthetics; Science; Mimesis; Play

\section{Introduction}

It is usually assumed that each discipline ranging from the humanities to the sciences forms a neat, separate and irreducible mode of analysis and area of expertise. The great body of knowledge accumulated over time, is a testimony to the many advances in each field. Often new fields and sub fields are established, but in the main there appears to be a separation between the humanities and the sciences; two cultures as it has often been described. While this is a useful partition, it may be but a fiction. For whether one is talking about either such disciplines, it remains human knowledge all the same and therefore subject to the same perceptual apparatus and history, albeit science claims neutrality and objectivity, while the humanities and the arts, the subjective and more imaginative domain. Nevertheless, such distinctions may be spurious and shortsighted. My endeavor is to suggest some rudimentary language, albeit far from a written system of codification or discipline, but described as a more holistic conception of the "state of knowledge" as it were. It is here that one may speak of the inter-disciplinary and I do this by some philosophical speculations wherein art and science can share a common language of sorts.

A thought experiment may be useful to develop this argument: Consider a time in prehistory, in fact at the dawn of what may be described as civilization and man's early encounter with a never-before-seen animal, what may be dubbed in English, as a dinosaur. That first enigmatic and frightening sight and auditory experience may be too much to bear for our early ancestor, a perceptual experience that motivates flight most likely, an instinctual reaction. But then our intrepid explorer might realize that this animal would feed his clan and so he may be daring enough to divine methods to hunt it. In order to do so, he becomes, perhaps unwittingly, our first researcher. Cultural development may make of him an artist and/or a scientist.

\footnotetext{
* Corresponding author: Daniel Shorkend

Technion Institute of Technology, Haifa, Israel.
} 
He has come to realize by this stage certain logical laws: what appears to be in one place cannot be in another place at the same time. That such beasts, call it x seems to be in a similar place at a similar time and by tracking, he realizes that in fact $\mathrm{x}$ comes to feed and drink at certain spots and is perhaps attended by other such beasts which look similar. Through observation and study, he builds a picture so that what was terrifying and undefined, becomes more defined and understandable. He begins to manipulate his environment as a result and gains just a little mastery of what we call nature.

Let us pause and note the steps here: First is the aesthetic experience and the frightful emotions attending such an experience. Then, as is wont of humankind, he tries to understand and overcome this threat. He may have some rudimentary language, far from a written system of codification, but nevertheless sophisticated enough to begin a) naming, b) counting and c) making art.

Such advancement in what may be called conscious human experience enables him to overcome his weak physical disposition and make-up and best even a beast 100 times his size, ten times his agility and so on. Now the point I wish to focus on in this: That first perceptual experience may be described as aesthetic. A meeting point between what is "given" in the world of phenomenon and the sensory apparatus endowed by nature. It is that what I call an "epiphany" that gives rise to the subsequent motor response of running and survival and then the later experience, of analysis and comprehension.

Fast forward in time and one might define such a) naming as oral knowledge that takes the form of literature in the form of writing; b) counting, that develops into the field of mathematics and its application in the sciences, and c) art, namely the highly developed cultural expression of the visual, musical, theatrical arts. Yet, such dividing is only as a consequence of that initial epiphany and subsequent analysis and control, and are in fact undefined at its source. The confrontation of man and nature is inherently then an aesthetic event.

What I have been describing may be understood as the relationship between abstraction and sensuality. The impossibility of accurate resemblance can be described as the limiting device of the form/vessel (for example, a painting), but the partial success of the aesthetic function explains the way "light" (by which I mean, an idea, an object, the senses, language - though in relation to one another they can be "vessels") takes on structure or is contained and is manifested. Ways in which the "light" is articulated necessitates forms/"vessels", though in relation to one another the designation "light or "vessel" may interchange. For example, a sunset may be described as "light" and the recording of that scene by way of a painting can be described as a "vessel", though the latter is "light" in relation to a text written about that painting and so on. The following are some examples of "lights" or "vessels":

- $\quad$ Number (the basis of abstraction): the nine digits plus the cipher, zero refer to quantity and allow the material world to be packaged in various ways through which we seek a certain control. Numbers "contain" objects and in being assigned a number the objects can be said to mirror one another (for example, "there are billions of galaxies" means "galaxies" in view of resemblance can be accounted for and indeed, counted).

- The faculty of sight: this determines a pre-cognitive relationship between the observer and the observed. Art stems from this faculty primarily and script is a later invention. A world labelled and dissected dims the faculty of vision. On the other hand, verbal language in a sense assists one to see.

- The faculty of hearing: this determines a pre-cognitive relationship between the hearer and the sound of something and is more ephemeral and less expansive than sight. Music stems from a consciousness of this faculty, and speech is the unique wonder that makes use of sound and the evolved mechanism of breath, larynx, tongue, teeth and lips. I would imagine that an analysis of music and speech could further assist one to hear more nuances in sound, whether it is music or speech.

This distinction between "lights" and "vessels" renders the mimetic function not so much a copying of reality through another, but the incommensurate nature of one language in relation to another, that is, the limitations inherent in the very notion of transcribing one order of experience into the language of another. At the same time, this is concerned with the possible interconnection between the language, discipline and "form of life" between two different kinds of expression. (C.f. Hey, T and Walters, $\mathrm{T}$ in The New Quantum Universe (2003) for an explication of the fundamental inaccuracy of experimental and sensory measurements). Evolutionary biology can be seen as a precondition to cultural expression. Or in other words: Art and science are simply different kinds of investigations into the heart of reality/matter/nature.

- $\quad$ Smell, taste and touch form separate categories and in various ways impinge on our language development, both artistic and linguistic and are perhaps "older" than sight and hearing. 
- Body movement: this determines both a language of relating to the world guided by the senses and could also be codified as dance, sport and the like. The body-mind is free within certain constraints, that is within the limits of the human body and the environment in which it finds itself.

- Language: this determines both a pre-cognitive awareness of Other and a conscious learning that names Other (and self). It is somewhat removed from the "given" for, like number and abstraction, language is a symbolic system. Meaning via language is also cultural, contextual and changes over time.

The above six aspects of filtering feed into various languages, each of which are only partially translatable one into the other, which is not to preclude their interconnection. One such modality is scientific; another artistic - though they are of the same order at its source.

Given these six mediation devices, each of which is interrelated, there is a "presence" - an aesthetic sign - and an "absence" - extra-aesthetic meanings (which themselves are aesthetic). The relationship between sign (sensuality) and referent (abstraction) has been problematized in thus far. Art functions to create meaning in the oscillation between "presence" and "absence" and it can be argued that science as a highly cultural, developed "body language", may also be interpreted and perceived to do just that. I use the concept of mimesis and the differing time-dimensions, in order to describe the overarching theoretical substrate in the development of both art and scientific exploration.

The spiral image most interestingly illustrates the idea that the initial "point", that represented by the "realm preceding thought" or the "given", leads out into the senses, then art (or science) and at the outskirts of our imagined spiral, language. This may be generated "back" towards that "initial point". Plurality of chains linking language (extraaesthetic meaning) to art/science (aesthetics), the senses and the "given" iterate the spiral with infinite possible configurations. The point of "origin", the "given" is all that is present and yet all that is present is a mediated "garb". It is unclear to what extent each level mimetically reflects the level preceding level.

One might distinguish "orders" of mimesis: In a hermeneutic approach, Degenaar (1993) distinguishes between the premodern, the modern and the postmodern. In summary fashion, he says that the first involves a lack of critical awareness; the second is concerned with modern rationality, while the last is the postmodern lack of trust in reason and the recognition of complexity, namely that there is no central point. The first paradigm can be said to inhere in the Middle Ages; the Renaissance can be described as partaking of both the first and second paradigm while the last is of particular relevance to contemporary art theory and practice. I shall explicate these "eras" in what follows in order to demonstrate that mimesis as a concept has changed in meaning over time. Preceding the pre-modern is prehistory, an amorphous pre-writing stage that integrates the epiphany - that confrontation to nature - without the cultural distinctions such as science, art, dance and so on. This is not to implicate a teleological unfolding and development, which is a modernist "tenet" as will be explicated, but that the very concept of a theoretical construct such as mimesis is problematic and thus mimesis is rendered void of "truth", as the copy and original, theory and reality, art and life distinctions are "eroded". This lack of "truth" does not, as hitherto stated, preclude meaning, but it does entail relinquishing the idea that mimesis is a reflection of - and correspondence to - a defined reality. In fact, why should art be treated as a form of propositional knowledge with a logical truth claim, as representing reality? Surely art as an imaginative activity does not conform to mimesis strictly defined as accurate resemblance? In this light, the shift in the meaning of mimesis as not simply correspondence thinking seems to me to make sense. The result is that form is not a transparent revealing of a definite content.

\subsection{The first "order"}

According to Haldane (1992:279-282), the art of the Middle Ages was based on the assumption that beauty exists independent of human awareness and involves a connection to the divine, to metaphysics and theology. There is an integration of religious, moral, political, scientific and artistic values - extra-aesthetic concerns - so that beauty and goodness are said to be aligned and fulfils a designated social function, namely the visual description of - and correspondence to - the narrative of the Christian bible, a pre-given structure or pattern. Moreover, the human figure in medieval art is without solidity and there is little awareness of the natural environment. The figure is a mere icon existing in some timeless state. In this sense, the Word is primary and the image was used not to depict pictorial reality, "but rather the divine biblical order, one imbued with harmony, truth and goodness" (in Haldane 1992:281), so that artistic, aesthetic beauty was not autonomous, but represented the beauty of "G-d's Word" and was useful, both didactically and politically in the Middle Ages of Europe. Simply put: a specific aesthetic was said to correspond to a specific extra-aesthetic set of meanings within a particular historic time and place. 


\subsection{The second "order"}

In the Renaissance, the mimetic function in art reveals a surface that belies a "deeper" truth. The artist gained more independence and so this "truth" can be perceived also as the creative intention of gifted individuals. However, during the Renaissance, there was still a dominant program that the individual subscribed to in one way or another, namely that art reflected some sort of idealization and idealization of order in variety. In this sense, there is a kind of ontological aesthetic "depth" with which art corresponds. An exemplary quote in this regard is Aquinas (1225-1274) who defines beauty as: "...integrity or perfection (integritas sive perfectico); second, proper proportion or consonance (proportion sive consonantia) and third, clarity (claritas)" (Summe theologiae 1 q. 39 a.8). "Beauty" is thus a transcendental quality identical in an entity to the things being, its unity, its "goodness", and its "truth". Sartwell (1992:46) therefore says of Renaissance painting that it is "simply imitation of all the living things of nature with their colours and designs just as they are in nature". There is, therefore, the notion that the sensible symbolizes the transcendent and thus "in making things according to due proportion as in the work of the arts, one creates beauty and, ipso facto, establishes a link with the Divine" (in Haldane 1992:281). This led to what may be termed humanistic naturalism, and was made possible technically by the innovations of perspective and the study of anatomy. This is reflected as follows in Alberti (vol. 3:52): "the function of a painter is to draw with lines and paint in colours on a surface any given bodies in such a way that at a fixed distance and with a certain position what you see represented appears to be in relief and just like those bodies". Leonardo claims that the mirror should be your master (Treatise on painting in Haldane 1992:282). Painting thus could be reduced to a mathematical order and was part of higher learning - art being subjected (reduced) to a kind of science of copying nature.

One could sum up by saying that both the medieval artist and Renaissance artist imitated a pre-established world order both derived from the Christian bible - its extra-aesthetic reference - and to which a specific art aesthetic is said to correspond. However, the former did so without recourse to an accurate recording of the empirical world; while the latter, in a movement towards a secular, modern, Western world-view, regarded naturalism as the means for communicating "the Word" in visual, more empirically accurate term and what may be termed, a scientific paradigm. This accuracy, a certain classicism, was held to be the benchmark of "good" art, but modernism sought to supplant this mimetic ideal and develop an alternative aesthetic and mimetic ontology. I shall deal with this in what follows.

\subsection{The third "order"}

The onset of modernism is debatable. I will be focusing on the modernist aesthetic especially as it took root in twentieth century abstraction and abstract expressionism. I will be presenting the ideas as "the modernist" (artist) may have seen it and thus uncritically, but one should bear in mind that the modernist art for art's sake dictum, in many respects the formalist approach, assumes an ontological mirroring of an aesthetic "depth", and that abstraction itself theoretically implicated a teleological mirroring of an aesthetic "depth" as well, indicative of the procession of early to midtwentieth century art movements or in short: the avant-garde. This section ends off with the argument that the modernists aim to reconcile opposites between say spirit and matter, ideal and real, art and life, subjective and objective, with the idea of a "depth" and the like, ended up with Adorno's negative dialectic and the sense of a failed utopia, thus negating, to some extent, the idea of an artistic ontology. Thus, one is left with the kenosis of abstraction. I would conjecture that such shifts in art mirrored the rise of science and the movement from classical to modern physics.

I shall begin this account with Kandinsky, usually dubbed as the first abstract painter. Wassily Kandinsky (1866-1944) eloquently describes his exploration of the metaphysical by means of abstract art: "speaking of the hidden by means of the hidden. Is this not content?" (in Thomas 1976:34). In order to achieve this, Kandinsky worked both with the element of chance, the unexpected and the attempt to clarify a symbolic colour notation that would mirror laws of the cosmic dimension. The cosmic dimension is an assertion of both the subjective and the objective, which one might argue reflects the concern of modern science, where the observer is said to act upon that which is observed and thus becomes part of the experimental context. His paintings therefore reflect a holism of personality, the direction of will to thematise, to use Wollheim's terminology, in order to tap into a higher dimension. This can be described as the visual analogue to music and thus a kind of mimesis from one area of expression in terms of the language of another, namely the visual. When Kandinsky saw in his upside-down painting a certain formal coherence and meaning, it was probably not just aesthetics and more specifically formalism that interested him. He had altered perception and thus, conception. Gombrich (1959:303) expresses it in these terms: ...in turning away from the visible world, art may really have found an uncharted region which lies to be discovered and articulated...this inner world, as we may call it so, can no more be transcribed than can the world of sight. Again, one might link this to the scientific exploration of the large via telescopes and of the incredibly small via the microscope and particle accelerators.

To the artist, the image in the unconscious is a mythical and useless an idea as was the image on the retina. There is no short cut to articulation. Wherever the artist turns his gaze he can only make and match, and out of a developed language 
select the nearest equivalence. It appears then that painting approximates what one wishes to "say" concerning the inner world. We might say that the language of art is miraculous not because it enables the artist to create the illusion of reality but in that "it teaches us to look at the visible world afresh; it gives us the illusion of looking into the invisible realms of the mind" (Gombrich 1959:329). In a sense, abstract art and abstraction is not new, for mimesis is an abstract process. Even Constable, a quintessential realist spoke of the scientific "breaking up of nature" and reassembling it (Hughes 1991), in order to reconstruct a semblance of the form of nature on a flat plane. Thus there is - at what level is uncertain - the intervention of the human mind, interpretation and filtering in all art. Here, one might say the reductive sciences explores reality as such by breaking it up into parts and analyzing the resulting details.

The modernist third "order" is merely a consciousness of those constituent elements, and in some forms of abstraction a reemployment of those formal aesthetic devices to elicit meaningful content and claims to truly reflect "reality". Pretwentieth century painting from the Renaissance onwards is based on the empirical world or uses images recognizable from the world in order to express an idea, a story. Painting of the early to mid-twentieth century, however, in particular epitomized by abstract expressionism, begins with a form that reflects consciousness, precluding direct references to nature, in order to access profound truths or the collective unconscious in Jungian terms. Jung (1983) developed the idea that there is a common template of universal archetypes that form the basis of the collective unconscious impinging in various ways on the individual's consciousness.

In a brief overview of select "abstract" artists I will argue for the mimesis (read: visual aesthetic correlate) of these truths. Piet Mondrian's (1874-1944) paintings reveal a philosophy where simplicity becomes the ultimate state, evolution a natural and mystical phenomenon, that is, the concern with pictorial reality or logic. The search for simplicity, that there is no one dominant force, that there ought to be balance and equilibrium, destroys the distinction between figure and ground of a painting, and by extension, in the area of philosophy, that between matter and nonmatter. In scientific terms, one might make the distinction between matter and light. The water, pier, sea and sky behind the configurations dissolve as the relationship between the lines assume importance. Mondrian saw abstract art as liberating the old forms of oppression, a religion of sorts. He was trying to search for something beyond nature, a metaphysical substrate, as he reveals in the statement: "we need to look past nature, but in a sense see through it" (Thomas 1976:13).

Here the mimetic function is thus to provide a kind of structural scaffolding behind the visible in terms of visual form, an underlying structure that the tangible world of objects share. In other words, he provides a picture of the unity of the external world. Mark Rothko (1903-1970) asserts "painting is a means of philosophic thought" (in Polkain 1991:59). His paintings are an arena where unity and wholeness are expressed through large canvases of close-valued hues whose feathery edges are almost connected with the boundaries of the canvas. There is a sense of the loss of the individual in the "all" through colour and the negating of form and line. The flat form destroys illusion and reveals truth, the being of the painting-object. An exhibition in 1947 organized by Barnet Newman called the "ideographic image" reveals the common project of many abstract painters of the time, namely a concern for pictorial truth, a presence within the canvas surface. Rothko even referred to his shapes of colour as organisms, entities that have volition. Others, such as Reinhardt, achieved this presence of being in his paintings by eliminating elements for abstract painting. In his philosophy outlined in his essay 12 rules for an academy (1962), it becomes clear that through negation he attempts to arrive at the absolute, the empty, a kind of meditation and silence, and painting as an end in itself. Thus, one can describe the works of Rothko, Newman and Reinhardt as the attempt to mirror, as in mimetic resemblance in visual terms concepts such as "silence" and "meditation" or the gestalt of colour itself, such as the red of red.

Jackson Pollock's (1912-1956) paintings of 1947 to 1952 reveal a network of lines and inscribe the visceral aspects of the artist's energy at the moment of each works creation. There is a flow of the artist's being at the moment of each works creation. There is a flow of the artist's psychic energy and physical movement, as complex webs of poured and strewn lines, splattered puddles and coalesced pools of paint, develop. The influence of surrealism is important, though it can be said that they merely illustrated a magical world, rather than created it. Pollock saw his role as a kind of creative shaman. "I am nature", he exclaimed, not merely inspired by nature, but being a conduit of nature itself.

This is not necessarily a stance of anti-intellectualism, rather it is an attempt to reconcile secondary (logic) and primary processes (poetic license) in a unity of unmatched intensity. His primal "drips" is a kind of mimesis of himself, that is, a record of his own movements reflecting that he is part of nature, not simply copying nature at a removed distance. The innovations of the abstractionists of the twentieth century shattered preconceived notions of painting, painters and the painting-object and opened up the area of painting to an individual form of expression that explored the deep consciousness of the mind, creating new icons. One might be so bold as to claim that they were then monuments of a new faith - again all such statements are a presentation of modernist rhetoric presented uncritically. 
Both formally (aesthetically) and conceptually (extra-aesthetic references), the notion of mimesis was no longer a subservience to a likeness that could be observed or derived from the biblical source, or observed reality, but assumed a more abstract reality. The term "abstract" does not imply "without form", but rather without dependence on the forms historically incorporated in art. There is a new system of reference as Newman (Pohribny 1971:65) was quoted saying: "... there is no good painting about nothing". So that in a certain sense it is still "painting as a window into..." transporting the viewer (in)to another dimension. In such terms, one can describe Pollock's work as wild, but intelligent; Rothko's work often cries, but is meditative; Newman's work is mystical, but classic (rational); Reinhardt's work is solid, but light; Kandinsky's work is metaphysical, but full of the colours of the material world. In groping for descriptive words for these ineffable works we find that such art is, after all, referential and thus alludes to that which is beyond itself. Or in other terms: such abstract art aimed to be a mimesis of an ontological, pregiven aesthetic, a "depth" - an "inner world".

One may question whether modernism achieved the objective of finding this aesthetic "essence". In the face of two world wars the artistic enterprise and its idealism appeared to have little effect. Adorno (1984:2) puts it like this: "in the face of the abnormality into which reality is developing, art's inescapable affirmative essence has become insufferable". He therefore calls for the continual disruption of the status quo, a "negative dialectic" and a disruption of the modernist aesthetic harmony with its implications of an ontology and teleology. In other words: one may counter the aesthetics of modernism as revealing deep content, that is, extra-aesthetic references. The move "away" from thinking of an "essence", an "original", "truth" - an inner reality or extra-aesthetic "depth" - and the like has been theorized as a movement "towards" postmodernism. One might parallel such investigations as a kind of scientific laboratory peering into the very depths, the inherent abstract design of reality itself.

\subsection{The fourth order}

Many theorists such as Lyotard (1984) and others believe we have entered a new "phase" that is after modernism. This is the poststructural, deconstructive and postmodern "phase". It is useful to analyze its relation to mimesis and the other "orders" hitherto mentioned, with a view to replacing "truth as correspondence" ("orders" 1-3) with that of the lack of a "truth", and yet maintain artistic meaning and scientific truth, a point that Plato did not foresee. I shall define postmodernism and its discarding the "truth" function by contrasting it with the third "order" or modernism. The "third order" is modernist in that it demarcates a specific place for painting in contradistinction to other forms of art. It entrenches itself further within painting itself in the sense that abstract art can, for example, be considered a separate domain from other styles - and art as a completely separate domain to that of science. Moreover, it assumes the mimetic transparency of language and its capacity to represent an "inner" reality, a "higher" realm and assert the presence of the painting-object. In such terms, art is a separate activity from functional life.

Postmodernism, by contrast, recognizes the "impurity" of the medium, its lack of transparency, that is, its mimetic function, and thus the spilling over of mediums, styles, techniques and categories into each other. Moreover, it critiques artists as original and that their style merely serving to express the smooth line from internal states reliably mirroring external form. In terms of such a critique, art is not easily parceled off as a second-order reflexive activity. The boundaries between everyday life and art are not necessarily strictly defined and so the possibility of the interdisciplinary comes to the fore.

An image may be useful here to problematize and illustrate the complexity and the lack of transparency of the postmodern, and the impossibility of mimesis as a recording of one aspect of reality through another, that is, art as a second-order reflexive and mimetic activity. In short, I will problematize mediation (perceptual aesthesis), or "framing devices". The image I refer to is that of a Spiral. The "point" at the beginning of the spiral sequence represents the dimension preceding thought or it can represent a physical object or at least the reality of appearance. This is the given starting point, which is then "clothed" and described via sensory impressions and finally described at the "edge" of the spiral, by language. And yet, language potentially also links back to the realm preceding thought or the "thing" and the spiraling sequence is repeated. Art (and science) are somewhere between the senses and language. At the far reaches of nature, culture emerges. The point here is that each "recording" device (degree of mediation), from the reality of appearance or a reality preceding thought; to thought itself; to the senses; to the arts and verbal language, both reveals and conceals the level preceding it, thus distorting and attenuating that which one order of experience, for example, sight, expresses via another order of experience, for example painting. And to the extent that there is concealment, the mimetic function, construed as correspondence (as in "orders" 1-3) fails.

What I have been arguing for is that mimesis functions like a mask, and that while the modernist (third "order") took the "mask" to be real, a revelation of an essential underlying unity and principle, the postmodern (fourth "order") seems to recognize the "mask" for what it is, namely that the "mask" is deceptive, with no origin or mimetic imprint. Is this not what concerned Plato, namely in the rendering of the shadow reality, the appearances, there would be no recall of an 
original, his world of forms? The difference being that the postmodern embraces this uncertainty and considers it to be creative rather than halting the process with stable, metaphysical postulates! This creativity can be couched in terms of Baudrillard's (1988) concept of the "Simulacra" and "simulation". With these terms he wants to argue that we have no access to an "original", and more to the point, we cannot trace an artwork, for example "back" to an "original". The way we perceive or rather how we conceptualize what we perceive is already mediated via an endless array of surfaces and "copies". Baudrillard (1988:55) puts it in these terms: "the simulacrum is never that which conceals the truth ... it is the truth which conceals that there is none. The simulacrum is true". In other words, reality is replaced by symbols and signs that mediate "reality".

These "copies" cannot be said to be based on a reality, nor yet hide a reality, and they are infinitely mutable, changing and transforming, even as we attempt to grasp it. In terms of this theory we can say that historically, the premodern construes representation as a kind of artificial substitute for the real item, so that the uniqueness of objects and situations are real and signification gropes towards this reality. The modern, with the onset of the industrial revolution, began to blur the distinction between representation and reality when commodities became mass-reproducible, threatening to replace the "original", and modernist artists, taking (their) cue from the romantic, sought to find a place for art as a means of delivering back that "original".

With postmodernism of late capitalism, however, simulacrum precedes the "original" and thus the distinction between "reality" and representation vanishes. The result of this lack of a foundation, a "reality", is that rather than seek correspondence between art and life and life and an In-Itself, postmodern philosophy enjoins one to celebrate these surfaces, that is, the lack of a "deep" structure predicated on a unified theory, a clear aesthetic/extra-aesthetic correspondence. This reveling, as it were, in the "surface" can be understood as a playful and joyful way of theorizing the meaning of art and leads one towards a reconstructionist aesthetics in favor of one that is more inclusive. It sets in motion the possibility of expansive interpretation and "play". In this may similarly be applied to the scientific enterprise, one in which scientists or groups of scientists' "play" with ideas and mathematical formulations and models approximating reality rather than as a final description or picture of reality as such. Let us look at this "play" more closely.

\subsection{Huizinga's homo ludens}

In this section I develop an account of "play" drawn from the classical work on the subject, namely Huizinga's Homo Ludens. In the first instance, I shall explicate his account of "play" as integral to everyday life that does not appear to derive from postmodern thinking (the fourth "order"), being a work produced before the middle of the twentieth century. Huizinga appeals to notions such as "civilization" and man's "essential" nature. However, there is also a premodern unification of the dimensions of a society - artistic, sporting, scientific, legal and so on - under the rubric of "play" and I would argue that it is in this horizontal equalizing of all aspects of human endeavor or culture that his work coheres in some way with the postmodern, which is precisely a kind of equalizing of differences through the very notion of "play", a term that is not riddled with power, oppression and certainty.

In analyzing mimesis as "play", one deconstructs mimesis as a correspondence to an enduring "truth"; rather it is an arbitrary and creative vehicle for meaning-making. Ehrman (1968) and Fink's (1960) critique of Huizinga's sharp dichotomy between "play" and reality allows me to extend the argument that an art historical account of "play" is useful in illuminating or extending the power to represent/create, may allow one to see in science in a similar creative role. Huizinga (1949:7-8) notes that "play" has various meanings. He writes that "play" is more than just rational; it includes language as metaphor, which is a play upon words, sacred rites, mythology, law, science, commerce, art and games. But there is no exact definition, either logically, biologically or aesthetically. Generally, it is an interlude in daily life and interestingly it was Friedrich Schiller who proposed that ethical education, ennobling one's character could be taught through the fine arts, that arts "play" drive is a mediation and reconciliation between intellectual and sensuous matters and that aesthetics relates to that which is common to all fostering harmony (Schiller 1982). This does not contradict the idea that postmodernism also acknowledges difference.

My argument concerning mimetic "play" upholds both a universalizing, natural kind of concept and that it is arbitrary or conventionally constructed. Another way of saying this is that differences are maintained but not linked in any ascending or descending hierarchy and the contrast between "play" and seriousness is always fluid. There is also an arena in which "play" takes place like the stage, the court of justice, the screen, the field, the science laboratory... Furthermore, "play" creates order; and it may be connected to beauty, law, war, poetry, while including opposites - the tragic and comic. We refer to music as playing, dancing as essentially "play", and the plastic arts are less a matter of "play", though in terms of the search for new forms, the "play" element is crucial.. In all these cases, Huizinga (1949:21) considers true "play" as knowing no propaganda, and being a kind of "happy inspiration". I would argue that this "happy 
inspiration" is no less than a kind of reflecting of oneself through certain kinds of games, which are instances of mimesis. In other words, the game acts as a structuring device in which we can reflect on what ordinarily may go unnoticed when we are not ostensibly playing a game. As Henricks (1998:41) in an article on Huizinga writes: “... At such moments, people reconnoitre with eternity - or at least (to put the matter less grandly) concern themselves with matters that are timeless. This is very much the appeal of such activities; they allow us to experience 'eventfulness'”. Moreover, we should take Huizinga's cue that the nature of "play" is that it is fun. He describes "fun" as the essence of play, even though the word "fun" is only really found in English and is of recent origin. "Play" is therefore concerned with a spirit of cultural exchange as this "fun" is more than just a biological response to the natural world. We can thus deduce that creating an image and playing a game, such as scientific investigation, represents, and is itself a mimesis of, aspects of human "play", that are, in simple terms, "fun". I maintain that "play" is fun simply because we are able to "loose ourselves" in the game. "Play" is irrational in that it seems to serve no purpose.

The disinterestedness of "play" seems to be outside the immediate satisfaction of wants and creating order out of chaos ergo - the first chaos that was involved in our first experience of a dinosaur! In creating such order, temporary worlds within the ordinary world are conjured. Rather than the imperfection of life we have a temporary, limited perfection. Hence, we may also say it is beautiful and involves a certain tension, poise, balance, contrast, variation, solution and resolution. It may be enchanting, captivating, rhythmic and harmonious. It may also be an ethical training as "play" tests one's fairness in adhering to the rules of the game. "Play" therefore promotes the formation of social groupings; it is cultural. If the reader should retort that cultural "play" is actually a rather serious business, one would do well to recall that such terms of seriousness, such as that of the ideal of "zeal", "exertion" and "painstaking" are all qualities that may also be associated with "play".

Even in law and the juristic wrangling of a modern lawsuit, the seeming bastion of seriousness, one observes a sportsmanlike "playing" passion for indulging in argument. And in war, surely terribly serious, fighting may yet be bound by rules and therefore it "bears the formal characteristics of 'play' by that very limitation" (Huizinga 1949:89). And in music the perception of the beautiful and the sensation of holiness merge and therefore the distinction between "play" and seriousness is weakened in that fusion. In this sense, there is no clear-cut dichotomy between depth and surface; indeed, the everyday may be described as a kind of playful seriousness or beautiful struggle. Huizinga (1949) furthermore argues that the plastic arts, as opposed to music, dancing and some types of sport, are such that "play" is less evident. The plastic arts in Ancient Greece were not under sway of the muses (Apollo), but Hephaestus or Athena Ergane, the Athena of work. Such art is bound to matter and the limitation of form inherent in it. However, as much as plastic artists are inspired by the creative impulse, as is the scientific - they have to work like craftsmen, seriously and with intent, always testing and correcting themselves.

Though Huizinga (1949) does maintain that there is an element of "play" in enjoyment and the contemplation thereof, even if the art is not free, that is, it is commissioned. The visual arts may be considered less a matter of "play", unlike the musical arts that live and thrive in an atmosphere of common rejoicing, the plastic arts appeal to silence, an inner language. However, Huizinga (1949) goes on to say that there are traces of the "play"factor in the plastic arts. Buildings, garments, weapons beautifully ornamented contain a sort of mystic identity, a magic power, in their functional role as part of a ritual context - in this there is "play". In this sense, like music, to decorate an ornament and make resplendent is to create a culture of "play", though we should be weary if it is used to adorn a political regime that is dangerous, for example, just as science may transmute into the designs of weapons of war.

Ehrmann (1968) and Fink's (1960) critique of Huizinga avoids this kind of pessimism and they argue in turn that "play" does not take place in isolation from or in opposition to the rest of reality. Rather "play is...coextensive with and reflective of culture as a whole" (Fink 1960:86) so that to "define play is at the same time and in the same movement to define reality and to define culture". (Ehrmann 1968:125). In fact, the split between "play" and seriousness in Western culture may be traced back to the eighteenth century Enlightenment, whereby "play" is seen as mere adornment of "reality" which if subtracted would leave "reality", albeit dull and ordinary. I suggest that this rift could be restored if one reclaims art as mimetic "play" in the postmodern sense and apply the symbolic (extra-aesthetic) and aesthetic values that pertain to art to other cultural dimensions, such as indeed, science.

Thus aesthetics, alongside studies in sociology, history, politics and so on may, for example, illuminate and even extend our understanding of the mass (post-)modern fascination with science. Fink (1960) offers a way to consider "play" philosophically that lends itself to how art (history) in particular may be useful in extending on our understanding of science. Opposing Huizinga's play/reality distinction, he argues that "play" absorbs "reality", "seriousness", ...through representing them. In a sense, we even play at being serious so that we are able to consciously exist in two different spheres at the same time. I would argue that "play" is often precisely that capacity that enables the scientist to withdraw temporarily from the real world, and to assert his or her freedom by recreating it imaginatively, without losing touch 
with reality. In this sense the relationship between "play" and "reality" is not antithetical but symbolic. In such terms, the "play" world acts as a mirror of behavior in the real world; the player is both object and subject. I would claim that art is the quintessential case of this kind of mimetic "play" and conceived in these terms, science as "play" is also a (re)creation of a symbolic, no less than an aesthetic "world" that resembles what we call the "real". In that resemblance or mimetic "play", science, like art may allow for a vision (image) of reality itself or of what it could be like.

\section{Conclusion}

In this article, I began with a thought experiment of our primeval ancestors and described in short thrift the subsequent movement from a terrifying and awe-inspired initial experience with a never-before-seen animal towards the conquering of the beast through what later became the arts and sciences. I developed the argument that such cultural evolution is attended by various mediation devices - our perceptual and analytical apparatus - and that this can be understood in terms of four orders of mimetic resemblance.

The last of the four, the postmodern allows the possibility of integrating these various disciplines or modalities and this is afforded through a conception of "play". Huizings's homoludens was used to argue as such. This article then hints or suggests at an interdisciplinary language wherein the arts and sciences may be similarly understood as necessarily aesthetic, with the far-reaching vision of the future artists and scientist working together, sharing a language towards a more holistic knowledge base and a better, more awe-inspired appreciation of the "given", wherein nature and culture are less at odds, and more seamlessly envisioned necessarily.

\section{Compliance with ethical standards}

\section{Acknowledgments}

I acknowledge this assistance of the Technion Institute of Technology.

\section{References}

[1] Adorno TW. Aesthetic theory. London: Routledge \& Kegan Paul. 1984.

[2] Baudrillard J. The ecstasy of communication. In postmodern culture. Foster, H (ed). Translated by J. Johnston. Port: Bay. 1983; 126-134.

[3] Baudrillard J. Simulacra and simulation. Michigan: Ann Arbor (University of Michigan Press). Baudrillard, J. 2000. The vital illusion. New York: Columbia University Press. 1994.

[4] Degenaar JJ. Art and the meaning of life. Published paper. Cape Town: Department of Adult Education \& Extramural Studies of the University of Cape Town. 1986; 39-46.

[5] Fink E. The ontology of play. Philosophy today. 1960; 4(2): 95-109.

[6] Gombrich E. The story of art. London: Phaidon. 1960.

[7] Gombrich E. Art and illusion: a study in the psychology of pictorial representation. 5th edition. London: Phaidon. 1962.

[8] Gombrich E. Meditations on a hobby horse and other essays on the theory of art. London: Phaidon. 1967.

[9] Haldane J. Aquinas, Thomas in A companion to aesthetics, edited by DE. Cooper. Oxford: Blackwell. 1997; 9-11.

[10] Haldane J. Medieval and renaissance aesthetics in A companion to aesthetics, edited by DE. Cooper. Oxford: Blackwell. 1997; 273-283.

[11] Huizinga J. Homo ludens: a study of the play element in culture. Suffolk: Paladin. 1949.

[12] Hughes R. The shock of the new: art and the century of change. London: Thames \& Hudson. 1991.

[13] Lyotard JF. Complexity and the sublime. In: Postmodernism. L. Appignance 301 (ed.). London: Institute of Contemporary art. 1986.

[14] Pohribny A. Abstract painting. Oxford: Phaidon. 1971.

[15] Sartwell C. Representations in A companion of aesthetics. Edited by DE Cooper. Oxford: Blackwell. 1992; 364-369. 